July 1984

\title{
Chronic Pain
}

Roberta Ball, DO

Thomas Jefferson University Hospital

Follow this and additional works at: https://jdc.jefferson.edu/jeffjpsychiatry

Part of the Psychiatry Commons

Let us know how access to this document benefits you

\section{Recommended Citation}

Ball, DO, Roberta (1984) "Chronic Pain," Jefferson Journal of Psychiatry. Vol. 2 : Iss. 2 , Article 3.

DOI: https://doi.org/10.29046/JJP.002.2.002

Available at: https://jdc.jefferson.edu/jeffjpsychiatry/vol2/iss2/3

This Article is brought to you for free and open access by the Jefferson Digital Commons. The Jefferson Digital Commons is a service of Thomas Jefferson University's Center for Teaching and Learning (CTL). The Commons is a showcase for Jefferson books and journals, peer-reviewed scholarly publications, unique historical collections from the University archives, and teaching tools. The Jefferson Digital Commons allows researchers and interested readers anywhere in the world to learn about and keep up to date with Jefferson scholarship. This article has been accepted for inclusion in Jefferson Journal of Psychiatry by an authorized administrator of the Jefferson Digital Commons. For more information, please contact: JeffersonDigitalCommons@jefferson.edu. 


\title{
CHRONIC PAIN
}

\author{
ROBERTA BALL, D.O.
}

A complex problem of vast dimensions, chronic pain is receiving increasing attention due to the expansion of knowledge of the neurophysiology, neurochemistry and psychology of pain. Chronic pain presents a challenge to many disciplines in the health professions, and one that is more recently being presented to the psychiatrist. This paper will attempt to define the problem of chronic pain, to explore the concept of organic versus psychogenic pain, to describe the psychodynamics and other characteristics seen in the chronic pain patient and to discuss the importance of the psychiatrist in evaluation and treatment of chronic pain.

\section{Epidemiological and Historical Aspects}

A complaint of pain, in one form or another, is reported to be the most common reason patients seek medical treatment. It has been estimated that over one-third of Americans have persistent or recurring pain which requires medical attention and that over 50 million people are either partially or totally disabled by pain for periods ranging from a few days to weeks, months and, in some cases, many years (1). Pain results in the loss of approximately 700 million work days per year, which represents a cost to the national economy of between $\$ 85$ and $\$ 90$ billion annually in health care costs and compensation. More staggering than the economic impact is the cost in human suffering and disability, which seriously impair the quality of life for so many people.

Focus on chronic pain, and on its diagnosis and treatment, began in the early 1950's with the work of John Bonica (2). His classic book, The Management of Pain, described all aspects of pain and its management, stressing the role of emotions in influencing the painful experience and proposing the concept of specialized units and a multidisciplinary approach to pain management. Modern theories of pain perception are based on work done in neuroanatomy, neurophysiology and neurochemistry. During the 1960's, the study of pain acquired several new dimensions. There developed an increasing awareness of the insufficiency of the biomedical model and recognition of the importance of psychological, social, and behavioral factors in pain. In 1965, Melzack and Wall (3) proposed their well known gate-control theory of pain, which postulates the central modulating and activating systems that influence the experience of pain. This theory provided new insights into the discriminative, affective and cognitive aspects of the painful experience. Fordyce and his colleagues (4) demonstrated the role of learning and behavior theory in chronic pain, which lead to new

Dr. Ball is a fourth-year resident in Psychiatry. 
concepts of pain management. The concept of the multidisciplinary approach to chronic pain became more evident in the 1970's, and resulted in the formation of the International Association for the Study of Pain (IASP) in 1974. The American Pain Society (APS) was founded in 1979. Focus on chronic pain continues into the 1980's with the growth of pain control centers which are responding to the enormous cost of chronic pain and to the waste of human resources.

\section{Definition and Phenomenology}

The word pain is derived from a Sanskrit root, $P u$, meaning sacrifice, and from the Greek word poine and Latin word poena, which mean penalty or punishment (5). In its semantic origin, the experience of pain implies the concept of retribution, with suffering as a process of penance and atonement. Both the Old and New Testaments give descriptions of chronic pain and suffering. Aristotle (6) viewed the experience of pain as "a passion of the soul," as a feeling rather than a sensation. This concept of pain as a passion of the soul was accepted within the Judeo-Christian tradition, and human suffering was accounted for as punishment for sins. Current attempts to define pain range from C. S. Lewis' "Pain is an experience, whether physical or mental, which the patient dislikes" (7) to R. A. Sternbach's "Pain is an abstract concept which an observer may use to describe 1) a personal, private sense of hurt; 2) a harmful stimulus which signals current or impending tissue damage; 3) a pattern of responses which operate to protect the organism from harm" (8). The subjective and multifaceted nature of pain is reflected in Mersky's definition, which was adopted by the IASP in 1979: "Pain is an unpleasant sensory and emotional experience associated with actual or potential tissue damage, or described in terms of such damage" (9).

Pain is a universal phenomenon. In its acute, pathogenic form, the experience of pain has a meaningful biological value as a warning signal of impending physiologic damage. It is usually characterized by relatively short duration, ends with blocking or removing of the nociceptive input, and fits the medical model of diagnosis, treatment and response. Chronic pain loses this function and becomes a self-sustaining disease entity which profoundly upsets the physical, emotional and social balance of the sufferer. Most authors use the term "chronic" for pain lasting at least six months. Hendler (10) described four stages of pain: Acute Pain (0-2 months), Sub-Acute Pain (2-6 months), Chronic Pain (6 months-8 years), and Sub-Chronic Pain (3-12 years). Crue (11) presents a useful taxonomy of pain based on etiological and temporal aspects: Acute Pain (up to a few days and due to nociceptive input), Sub-Acute Pain (from a few days to a few weeks), Recurrent Acute Pain (recurrent flare-ups of peripheral tissue pathology due to underlying chronic pathological entity), Ongoing Pain (continual pain in patients with malignant or terminal disease), and Chronic Intractable Benign Pain (long-standing refractory pain with the patient exhibiting either adequate or poor coping).

Though meant to imply the absence of a malignant process, chronic pain is far from benign. It is a pervasive intrusion causing much suffering and alteration in life style and taxing the endurance of the individual as well as those around him, including 
those from whom he seeks help. Black (1) describes the Chronic Pain Syndrome as that which, regardless of duration, is confirmed by a significant alteration in the patient's life style, his relations with other individuals, and failure to show any progressive improvement though rarely becoming worse. Chronic pain patients remain relatively stable while continually seeking help from the health care system and submitting to its many therapies. They often have multiple pain complaints many of which are inappropriate to existing physical problems or illness (1). Pinsky's (12) description of patients with Chronic Intractable Benign Pain Syndrome is as follows: they have ongoing pain, not due to neoplastic disease, and have no significant ongoing pathophysiology; they have had most, if not all, standard medical and surgical treatments without lasting success; they have relatively fixed mechanical organic belief structures with regard to bodily functions; their chronic pain has become the central focus of their thoughts, behavior and social relationships; they may have problems involving drug dependency; they have a history of inability to form any psychological view of life problems; they tend to exhibit symptoms consistent with alexithymia, in that they have difficulty verbalizing feelings and constricted emotional functioning; they are generally fearful and distrustful of Psychiatry and psychotherapy.

\section{Etiology}

Mersky's (9) definition of pain is very helpful because it encompasses the somatic and psychic components of pain. Too often the approach to chronic pain has been limited to a search for a single etiology, with the diagnosis determined solely by the presence or absence of organic or objective physical findings. If objective findings are present, a physiologic origin for pain is ascribed, and if objective findings are not present, the cause of pain is attributed to psychological factors. This view has reinforced dichotomies such as organic or psychogenic, physical or functional, pathogenic or learned, somatic or psychic and, at its worst, real or imaginary. Psychiatrists are often consulted when there are no objective findings and the referring physician seeks sanction for a psychogenic etiology.

Sternbach (13) stresses that all physical causes need not be excluded in order to acknowledge the presence and effect of psychological factors. He emphasizes that chronic pain is often exacerbated and perpetuated by a variety of psychosocial factors. Mersky (14) notes that the prolonged experience of pain can produce secondary emotional changes and can uncover previously defended intrapsychic conflicts. $\mathrm{He}$ views chronic pain as a sociomedical crisis which is marked by symptoms and incapacities which are more significant than precise knowledge of the origin of the pain. Hackett (15) has devised the Madison Scale, which he proposes can identify the patient for whom a psychiatric consultation is indicated:

Multiplicity: The patient presents with pains of more than one kind or in more than one place;

Authenticity: The patient must convince you that his pain is real;

Denial: $\quad$ The patient denies that emotional factors influence his pain; 
Interpersonal

Relationships: The patient uses pain to manipulate others;

Singularity:

The patient feels that no one else has suffered such pain;

Only You:

The patient states that you are the only doctor who can help;

Nothing Helps: The patient states that nothing you do will help.

Each category in the Madison Scale is scored form 0 to 4 . Hackett suggests that a score of 15 or higher indicates need for a psychiatric evaluation.

\section{Psychological Factors}

The psychological aspects of pain have gained much prominence in recent years. The medical model of diagnosis, treatment and response has not been successful with the complex problem of chronic pain. Sir William Osler (16) stated as early as 1892: "It is more important to know what kind of patient has the disease than what kind of disease the patient has." That emotional states are related to pain has long been recognized in Psychiatry. Breuer and Freud (17) noted pain as a significant symptom in hysteria. They regarded pain as a common conversion symptom which can have a somatic origin, but is increased and maintained by neuroses. Pilowsky (18) has reviewed the psychoanalytic paradigms, particularly psychodynamics as they relate to the understanding of pain and illness behavior.

In his classic paper, Engel (19) discussed pain as a psychological phenomenon and described his concept of psychogenic pain and the pain-prone person. In these patients pain is both a warning system and a mechanism of defense primarily evoked by psychic factors in the absence, as well as in the presence, of peripheral lesions. Pain serves an adaptive function in the psychic economy as it has acquired special meaning in terms of psychic development and function. Engel asserts that pain is intimately concerned with learning about the environment and about the body, and that it involved with the earliest object relations. Early childhood links are established between pain and punishment: pain is inflicted when one is bad. This, in turn, may become a signal for guilt, with pain as the medium for expiation and forgiveness. Pain also becomes associated early with power and aggression as a child discovers the effect of inflicting pain on self and others. A link is formed between pain and the real, threatened or fantasied loss of a love object, particularly when there is guilt for aggressive feelings toward that object. Pain-prone patients often experience pain in locations where pain was actually or presumably experienced by the lost person. Suffering may serve to reduce feelings of loss as well as to control one's own aggression. For some patients, pain may also be associated with sexual feelings with a tendency toward sadomasochistic sexual development. Conscious and unconscious guilt are often evoked by intense aggressive and sexual urges. These patients are characteristically depressive and pessimistic and seem to have no joy or enthusiasm for life. They tend to describe dramatically both the hardships of their lives and the extent of their suffering from pain and illness. Pain and suffering thus become their unconscious sources of gratification.

Blumer and Heilbronn (20) observed many similar characteristics in a series of 
studies of patients with chronic pain. Their evaluation of patients seeking surgery for relief of chronic pain consisted of a pain questionnaire, a psychiatric interview and a battery of psychological tests. These patients characteristically denied any emotional conflicts or difficulties with interpersonal relationships. Evaluation revealed sadomasochistic tendencies and infantile dependency needs, often manifested in a symbiotic relationship with their partner. Many patients revealed a history in which a close relative had pain similar to their own, and there was often a real or fantasied experience with a mutilated close relative. Also common was a history of relentless activity until their invalidism. In 1981 results from another series of studies led Blumer (21) to define the "pain prone disorder." The most striking feature he found was the patients' inability to express their emotions, or alexithymia. They were also stoic, overly controlled and action-oriented. Alexithymia is a term coined by Sifneos (22) which means "without words for emotions." Alexithymia has been correlated with somatization $(12,23)$. These patients are not psychologically introspective, do not have active fantasy lives, do not tend to remember dreams, and are preoccupied with details rather than subjective experiences. They are often good-natured and conscientious rather than angry and resentful. Depression in usually denied though depressive symptomatology may be present. The patients are preoccupied with somatic suffering and have underlying features of guilt, dependency and masochism. Pinsky (12) has similarly emphasized the alexithymic characteristics of chronic pain patients.

Psychological focus on pain in recent years has contributed significantly to the understanding and treatment of chronic pain. Utilizing learning theory, Fordyce (24) has expounded on the behavioral aspects of pain, focusing on the relationships between the person and his environment rather than the search for etiologic factors. He presents the concept of pain as a learned behavior. Such behavior may be either respondent or operant, depending upon whether it is reflexively or voluntarily initiated and may persist even when the underlying causes of pain no longer exist. The experience of pain with movement may cause the development of the behavior which is predicated on avoiding pain, resulting in degrees of immobility. These behaviors may be affected by either positive or negative feedback and therefore reinforced or diminished in intensity (25).

Pain behaviors may elicit responses such as attention or solicitous behavior from others or may result in obtaining medication or compensation. Fordyce (26) believes that reinforcement increases not only pain behavior but also pain perception. Pilowsky and Spence (27) emphasize the link between pain, illness behavior and the sick role, considering the intrapsychic and environmental determinants of pain. They find anger inhibition as a significant factor in pain. Prominent in the clinical picture are somatic preoccupation, disease phobia and conviction of illness, with the inability to respond to reassurance.

Szasz (28) describes the patient with chronic pain as having a "pain career" and participating in "pain games." He examines the meaning and use of pain in interpersonal relationships, including that with the physician. Sternback (12) analyzes the activities of patient, family and physician that center on pain. He uses the transactional analysis concept and emphasizes the use of pain as a form of interper- 
sonal manipulation and control. Zbrowski (29) studied the cultural aspects and stresses these as an important variable in determining pain behavior. Penman (30) emphasizes the importance of pain to the individual who suffers chronic pain. He has identified a group of patients who adapted to a particular way of coping such that when a diagnosed source of pain was removed they became clinically depressed.

\section{Case Studies}

The following cases illustrate many of the psychodynamics often found in chronic pain patients.

Case 1 A 36-year-old married female was admitted to the Neurology service for intractable headaches of 9 months' duration. She complained of severe pain ("pulling and pressure") across the fronto-parietal region which was constant and unremitting despite rest and various medications. The headaches began two days after she sustained an open-handed blow to the fronto-parietal area of her head during an argument with her husband. She described their relationship as very good until this incident, when he returned home late and was intoxicated and abusive. She denied prior abuse or fighting. She denied immediate pain or loss of consciousness, and she denied any past medical or psychiatric history.

Since the onset of her headaches, the patient made several visits to her general practitioner and to emergency rooms, and had one prior hospital admission for evaluation of the headaches, with no positive findings. Tests performed in addition to the standard tests included lumbar puncture, computerized axial tomography (CT) of the head, and an electroencephalogram (EEG). She described her pain as increasing in intensity in the past month and said that she had been unable to work at her part-time job. She reported spending time in bed, unable to perform previous activities. Most recently, she was referred to a neurologist and was again hospitalized for intractable headaches. During the hospitalization, physical and neurologic examinations, CT, EEG, and lab studies were unremarkable. The patient was to be discharged the following day. Psychiatric consultation was requested at this time.

The psychiatric interview revealed a depressed-looking female lying in bed with an icebag on her head. She quickly focused on her pain and on her concern for the etiology. She described the incident preceding the headaches and related in detail her subsequent doctor and hospital visits and her increasing disability. She stated that the only thing that relieved the pain was to keep her head still.

The patient is the third of three siblings and of Mediterranean origin. She described her early life as happy and said she was close to her mother. She married at 21 and came to the United States with her husband. They have been married 24 years and have a 12-year-old daughter and an 11-year-old son. Her father died in 1976 of a cardiac arrest, and her mother still resides in her native country. The patient recalled her mother often having headaches and taking to her bed, where she lay with slices of raw potatoes on her head to get relief. 
The patient reported a good marital relationship prior to this incident and denied any emotional conflicts. She described her husband's behavior since her illness as caring toward her, and her daughter as siding with the mother in anger toward the father. As she began to acknowledge anger and allude to underlying conflicts and sexual difficulties, her anxiety increased to a point where she could no longer pursue this topic, and she immediately re-focused on her pain and undiagnosed illness.

The recommendation at this time was for the patient to seek outpatient psychotherapy and for a trial of antidepressant medication. From this initial interview, this patient's chronic pain illustrates the following: (a) pain as a realization of denied dependency needs and an expression of hostile aggressive strivings; (b) maintenance of pain for secondary gain; (c) memory of a close relative's pain; (d) marked denial of any emotional or interpersonal conflicts; and (e) inability to identify and verbalize feelings.

Case 2 A 38-year-old married white male was admitted to the Neurology service for multiple pain complaints and associated weakness of lower limbs. The patient claimed no previous medical history and was well until an injury on the job two years ago. The patient was a construction worker for 12 years, often working overtime or on several jobs simultaneously. He fell on the job and injured his back, which left him with low back pain and neck pain radiating to both shoulders. Since then he had been to several doctors and had had several hospital admissions, with no positive findings. He had been unable to work and spent most the time at home. His complaints at this time included pain in the lower back, weakness in both legs, pain in the neck and shoulders, headaches, visual disturbances, epigastric pain, penile pain, and rash. Consultation requests included Neurosurgery, Gastroenterology, Urology, Dermatology, and Psychiatry.

The psychiatric interview revealed a quiet, soft-spoken male with constricted affect. He was cooperative and became more spontaneous as the interview progressed. He was coherent and logical, showing no evidence of a thought disorder. He was obsessed with a plethora of physical complaints and with the lack of positive findings. Despite his previous hospitalizations and tests without definitive findings, the patient's anxiety and concern about symptoms escalated. He was more concerned with finding a cause for his symptoms than with the changes in his life which had occurred since his injury two years ago, which included disability, inactivity, decreased sexual functioning, and increased dependency.

The patient was an only child brought up in a religious family. He described a happy childhood and said he was close with his mother and father yet left school at the age of 16 and married a woman six years older than himself. He described a life of relentless activity. He has three children and has worked industriously at several jobs to provide well for his family. His two oldest children are married, and a 16-year-old son is still at home. He described his family and relationship with his wife as very good. She works and has assumed much of the responsibility for the family as well as for her husband. He reported still being very close to his parents, who live less than a mile 
away and have been very attentive since his illness. He focused his anger on his employer for not recognizing the severity of his injury, for expecting him to return to work in the same capacity, and for not supporting his claims for compensation. $\mathrm{He}$ is involved in litigation.

The patient may exemplify Hackett's compensation neurosis: he is a blue-collar worker who has overworked to compensate for underlying dependency needs. He is a hyper-attainer with the history of hard work and relentless activity until he developed the incapacitating pain which legitimized his new role of dependency and entitlement. Recommendations included antidepressant medication and outpatient psychotherapy.

Case 3 The patient is a 52-year-old single white female presenting with complaint of chronic pain in the neck, shoulders, arms and low back. Her low back pain began twenty-five years ago following a fall and subsequent spinal surgeries. She described her illness dramatically and in great detail, focusing on her long and arduous involvement with the medical system. Despite several surgeries and trials of various analgesics, she has found no relief. The patient reported the onset of the neck, shoulder and arm pain on the right side approximately eight years ago, but could identify no precipitating event. She reported having been hit by a small falling object six months ago, and, since then, has experienced exacerbation of the neck and arm pain. Diagnostic studies, including X-rays and CT scan, showed no acute pathology. She is now involved in litigation from the recent injury.

She presented for the interview wearing a cervical collar adorned with a decorative scarf. She had a splint on her right forearm and moved with hesitation and grimacing. Despite this, she smiled broadly and pleasantly acknowledged acceptance of her fate.

She described her life as wonderful except for the pain and difficulty sleeping. She reported a beautiful family and an idyllic childhood. She is the third of five children of a close, religious family. Her mother was hard-working and her father extolled the virtue of never complaining and keeping a smile on one's face. He died eight years ago, but the patient saw no relationship between this event and the onset of new pain. She remarked that she had been his favorite. All her siblings are married and have "beautiful families," and the patient lives with her mother, never having been on her own and never having had any significant relationships. She briefly pursued a career which met with parental disapproval. Following her initial injury twenty-five years ago, she never returned to work.

This woman's cheerful presentation belied half a lifetime of pain and illnessrelated behavior which continue to permeate and define her existence. She was quick to deny any emotional problems as she expressed a noble suffering which allows her a refuge from intolerable underlying conflict.

This patient illustrates the following characteristics often found in chronic pain patients: (a) alexithymia; (b) marked dependency needs; (c) denial of emotional conflict; (d) repressed anger and inability to deal with aggression; and (e) underlying sexual conflicts. She was referred for physical therapy, a rehabilitation program and biofeedback. 


\section{Association with Psychiatric Disorders}

Chronic pain is often a component of psychiatric illness, and psychiatric illness is often exacerbated by the prolonged experience of pain. Depression is one of the most common psychiatric illnesses associated with chronic pain, and the relationship has been studied extensively. Hackett (15) distinguishes between patients with reactive depression, who usually acknowledge being depressed, from those with primary depression, who have vegetative signs but deny that depression might contribute to the pain. Blumer and Heilbron (31) view chronic pain as a variant of depressive disease. Pilowsky (18), Mersky (14), and Sternbach (13) have explored the association between pain and depression. More recently, studies have indicated similar results of Dexamethasone Suppression Test values and Rapid Eye Movement sleep latency in patients with chronic pain and patients with major affective disorders. These findings have resulted in the use of tricyclic antidepressant medication in the treatment of chronic pain.

Symptoms of pain can also be seen in anxiety disorders, with the pain complaint serving to reduce anxiety. Pain complaints are also seen in schizophrenia, organic psychoses and psychotic depression. In these cases the pain is often bizarre in quality and distribution and is rarely the only symptom.

In addition to more traditional psychiatric diagnoses, DSM-III provides several diagnostic categories relevant to chronic pain under the heading of somatoform disorders. Additional diagnostic categories which might be included in a differential diagnosis of chronic pain include factitious disorder, malingering, and addiction to opiate analgesics and/or sedative hypnotics.

\section{Evaluation and Assessment}

Most investigators advocate a biopsychosocial model for the evaluation and management of chronic pain. Assessment must begin with a thorough and complete history and physical examination with appropriate diagnostic studies when indicated. Many patients present with a lengthy list of prior evaluations, investigations and treatments. To assess the presence and degree of psychological factors, many investigators have developed questionnaires, inventories, scales and screening tests to be used in addition to existing psychological tests. Investigators utilizing the MMPI report find that in chronic pain patients there is a pattern known as the neurotic triad or conversion $\mathrm{V}$, with elevation of the Hypochondriasis and Hysteria scales and a relatively lower score on the Depression scale $(32,33)$. Sternbach (13) found the same patterns with most chronic pain patients, regardless of the presence or absence of objective findings. Fordyce (34) suggests using patterns of high frequency and low frequency behaviors from the MMPI to identify maladaptive behavior patterns.

The McGill/Melzack Pain Questionnaire was developed to aid the patient in reporting locus, intensity, temporal pattern, and quality of pain. It provides a way of evaluating the patient's subjective experience of pain. The patient selects words in 20 sets of adjectives that describe the quality of the pain. The adjectives represent 3 
classes of words (sensory, affective and evaluative), and responses are indicative of the organic and psychological component (35). The Symptom Check List-90 (SCL-90) is a 90-question self-report inventory that yields measurements of depression, anxiety, somatic concern, self-esteem, hostility, obsessive thoughts, phobia, paranoia and psychosis (36).

These self-report inventories aid in assessing the psychological component, selecting treatment, and monitoring effectiveness over time. Visual analogue scales are designed to measure the subjective intensity of pain by recording what is experienced along a straight line, the ends of which are defined as no pain to the extreme limit of pain experienced. This can represent any given time or an average over a given period of time (37).

Brena and Koch (38) designed a pain estimate model for classification and quantification of chronic pain states based on the measures of organic pathology and illness behavior. Organic pathology is physician-based and includes physical and neurological examinations, laboratory tests and radiological studies. Patient-based illness behavior assessment includes self-report of intensity using a visual analogue scale and intensity section of the McGill/Melzach questionnaire, an activity record, a medication record and the MMPI. This assessment yields a measure of pathology and a measure of pain behavior. Each ranges from 0-10 points and can be plotted on two axes. Brena and Koch described 4 classes of chronic pain patients (Figure 1).

This classification provides useful guidelines for treatment:

Class I: $\quad$ Avoid biomedical management and avoid reinforcement of sick role. Pursue pain control and rehabilitation programs with emphasis on drug detoxification and physical and behavioral modalities.

Class II: Avoid central analgesics, sedatives, anxiolytics, unnecessary hospitalizations and elective surgery. Encourage the patient to remain func-

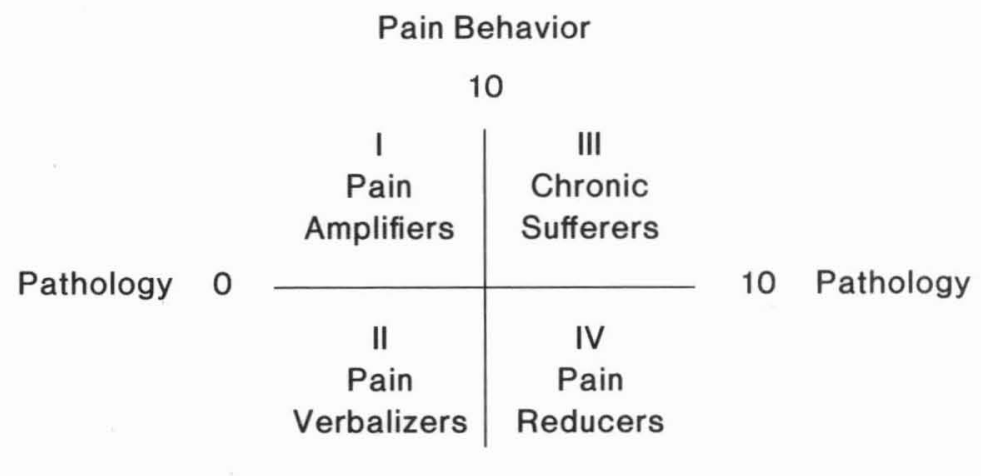

Pain Behavior

Figure 1 
tional. Consider physical modalities, mild analgesics, and antidepressants.

Class III: Use an eclectic approach combining biomedical management and pain control rehabilitation programs.

Class IV: Encourage the patient to maintain optimal functioning.

The Hendler Screening Test (39) is a fifteen-item questionnaire designed to classify patients with chronic back and limb pain into four categories which may be useful in predicting whether a patient may benefit from various treatments such as participation in a pain treatment unit, psychiatric therapy or surgical procedures. Scoring places patients into four subgroups with major parameters being the presence or absence of organic pathology and the patient's premorbid adjustment prior to pain. The Objective Pain Patient has a good premorbid adjustment and documented organic basis for pain. The response to pain will vary initially with eventual coping and good functioning. The Undetermined Pain Patient has a good premorbid adjustment with no known organic bases for pain. The response is similar to the first category. The Exaggerated Pain Patient has a history of difficulties in premorbid adjustment, and although there is documented organic basis for pain, the complaint of pain is usually disproportionate and magnified. Patients with various psychiatric diagnoses are found in this category. The Associative Pain Patient has poor premorbid adjustment and no organic basis for pain. Malingering, conversion reaction and psychosis are included in this group. Hendler suggests psychiatric intervention in the last two groups of patients.

\section{Pain Management and Role of the Psychiatrist}

The psychiatrist should be brought into a case as early as possible to participate in evaluation and treatment in a comprehensive manner as part of a multidisciplinary approach rather than to evaluate the functional versus organic nature of the patient's pain. Getto and Ochitull (40) present the following advantages to a psychiatrist's presence in a multidisciplinary setting: it legitimizes the role of the psychiatrist by allowing the patient to view psychological aspects of chronic pain within the context of medical illness; it provides the psychiatrist with thorough knowledge of the patient's physical condition; it allows integrated treatment planning, which alleviates the feeling on the part of the patient that psychiatric treatment is an afterthought; it allows integrated multidisciplinary treatment; psychological intervention seems to be more effective within a multidisciplinary setting which allows for individual, group, or family therapy. Intervention places the emphasis on changing patients' expectations from relief of pain to developing coping strategies which will enable them to alter the life style they have developed, which has come to be characterized by dysfunction, dependency, disability, inactivity, depression, and misuse of doctors and drugs.

Treatment planning should occur within a multidisciplinary context to select and coordinate the proper treatment modalities for the patient. Multidisciplinary approaches are found in highly structured pain clinics and in-patient pain units. As a 
consultant outside such facilities, a psychiatrist can evaluate, recommend treatment and serve as liaison to integrate treatment when several physicians are involved. Often the psychiatrist must deal with the frustration and negative feelings of referring physicians and must consider the function of educating colleagues about issues that underlie the patient's pain behavior.

The treatment of patients with chronic pain remains a challenge. A synthesis of clinical research suggests the following guidelines $(2,7,11,14,38,40)$ :

1) Avoid narcotic analgesics and abuse of sedatives and hypnotics.

2) If addiction is present, detoxification should be attempted, with substitution of aspirin or non-steroidal anti-inflammatory agents prescribed on a regular schedule.

3) Antidepressant medication has been found useful in alleviating depressive symptomatology, improving sleep, and increasing pain tolerance.

4) Avoid conceptualizing in terms of the organic versus psychogenic pain dichotomy, and acknowledge the patient's experience of pain while addressing his needs for immediate relief and longer-term goals of pain control.

5) Attempt to gain the patient's cooperation and participation in treatment, with the goal of having the patient assume more control and responsibility.

6) Emphasize rehabilitation with the use of physical therapy and selected physical modalities.

7) Help patients learn pain control methods through the use of hypnosis, relaxation techniques, and biofeedback.

8) Use behavioral modification techniques to deemphasize pain behavior and reinforce increased activity.

9) Individual psychotherapy, family therapy, and group therapy should be offered as part of a comprehensive treatment plan. Psychotherapy tends to be more effective when combined with other treatment modalities.

\section{Conclusion}

Chronic pain continues to be a challenging enigma facing many health professionals. Pain in its acute form has meaningful biological value but in its chronic form often evolves into a self-sustaining, destructive disease entity, heavily taxing the endurance of the individual sufferer and those around him. At present no single treatment modality capable of long-term control of chronic pain is available. A multidisciplinary approach aimed at the investigation of biological, psychological and social variables is necessary for meaningful intervention. It is within this context that Psychiatry can best contribute to the management of such a complex health problem.

\section{REFERENCES}

1. Black RG: The clinical syndrome of chronic pain, in Pain Discomfort and Humanitarian Care. Edited by Bonica J, Ng LKY. New York, Elsevier/North Holland, 1979

2. Bonica J: The Management of Pain. Philadelphia, Lea \& Febiger, 1953 
3. Melzack R, Wall PD: Pain mechanisms: a new theory. Science 150: 971-979, 1965

4. Fordyce WE, Fowler RS, DeLateur B: An application of behavior modification techniques to a problem of chronic pain. Behav Res Therapy 6: 105-107, 1968

5. Lidell, Scott: Greek-English Lexicon. Oxford, Oxford University Press, 1964

6. Hammond WA: Aristotle's Psychology: Treatise on the Principles of Life. London, Sonnenschein, 1902

7. Lewis CS: The Problem of Pain. New York, MacMillan, 1973

8. Sternbach RA: Strategies and tactics in the treatment of patients with pain, in Pain and Suffering, Selected Aspects. Edited by Crue BL. Springfield, Charles E. Thomas, 1970

9. Mersky H: A list with definitions and notes on usage. Pain 6: 249-252, 1980

10. Hendler N, Long D, Wise T: Diagnosis and Treatment of Chronic Pain. Boston, John Wright, 1982

11. Crue BL: Chronic Pain: Further Observations from City of Hope National Medical Center. New York, Spectrum, 1977

12. Pinsky JJ: Chronic intractable benign pain: a syndrome and its treatment with intensive short-term group psychotherapy. J Human Stress 4: 17-21, 1977

13. Sternbach RA: The Psychology of Pain. New York, Raven Press, 1978

14. Mersky H: The diagnosis of the patient with chronic pain. Postgrad Med 47: 572-580, 1971

15. Hackett T, Cassem NH: Massachusetts General Hospital Handbook of General Hospital Psychiatry. Boston, The CV Mosby Company, 1978

16. Osler W: The Principles and Practice of Medicine. New York, Appleton and Company, 1892

17. Breurer J, Freud S: Studies of Hysteria. Edited by Strachey J. London, Hogarth Press, 1955

18. Pilowsky I: Psychodynamic aspects of the pain experience, in The Psychology of Pain. Edited by Sternbach RA. New York, Raven Press, 1978

19. Engel GL: "Psychogenic pain" and the pain-prone patient. Am J Med 26: 899-918, 1959

20. Blumer D, Heilbronn M: The pain prone disorder: a clinical and psychological profile. Psychosomatics 22: 395-402, 1981

21. Blumer D: Psychiatric considerations in pain, in The Spine. Edited by Rothman R. Philadelphia, WB Saunders, 1975

22. Sifneos PE: Short Term Psychotherapy and Emotional Crisis. Cambridge, Harvard University Press, 1972

23. Lesser IM, Ford CV, Friedman CTH: Alexithymia in somatizing patients. Gen Hosp Psychiatry 1: 256-261, 1979

24. Fordyce WE: Pain viewed as learned behavior. Adv Neurol 4: 415-422, 1974

25. Fordyce WE: Learning processes in pain, in The Psychology of Pain. Edited by Sternbach RA. New York, Raven Press, 1978

26. Fordyce WE: Behavioral Methods for Chronic Pain and Illness. Saint Louis, The CV Mosby Company, 1976

27. Pilowsky I, Spence ND: Illness behavior and syndromes associated with intractable pain. Pain 2: 61-65, 1976

28. Szasz TS: Pain and Pleasure. New York, Basic Books, 1957

29. Zbrowski M: People in Pain. San Francisco, Jossey-Bass, 1967

30. Penman J: Pain as an old friend. Lancet 1: 633-636, 1954

31. Blumer D, Heilbron M: Chronic pain as a variant of depressive disease: the pain prone disorder. J. Nerv Men Dis 170: 381-394, 1982 
32. Prokop CK, et al: Multivariant analysis of the MMPI profiles with multiple pain complaints. J Personality Assessment 44: 246-250, 1980

33. Jamison $\mathrm{K}$, et al: Correlation of personality profiles with pain syndromes, in Advances in Pain Research on Therapy. Edited by Bonica J, Albe-Fessard D. New York, Raven Press, 1976

34. Fordyce W, Brena S, Holcomb RJ, et al: Relationship of patient and somatic pain descriptions to physician diagnostic judgements, activity level measurements, and MMPI. Pain 5:293-303, 1978

35. Melzack R: The McGill pain questionnaire: major properties and scoring methods. Pain 1: 277-299, 1975

36. Derogatis LR, Lipman RS, Covi L: The SCL-90: an outpatient psychiatric rating scale-preliminary report. Psychopharmaco Bull 9: 13-28, 1973

37. Rivill SI, Robinson JO, Rosen M, et al: The reliability of a linear analogue for evaluating pain. Anesthesia 31: 1191-1198, 1976

38. Brena S, Koch D: The pain estimate for quantification and classification of chronic pain states. Anesthesiology Rev 2: 8-13, 1975

39. Hendler N, Vierstein MC, Gucer P, et al: New diagnostic categories and a pre-operative screening test for chronic back residents. Psychosom Med 20: 800-808, 1979

40. Getto CJ, Ochitill H: Psychogenic pain disorder, in The Treatment of Mental Disorders. Edited by Greust JG, Jefferson JW, Spitzer RL. Oxford, Oxford University Press, 1982 